\section{A simple system for displaying alphanumeric characters on an oscilloscope using an AIM-65 microcomputer}

\section{LOTHAR KEHRER}

Abteilung für Experimentelle und Angewandte Psychologie Universität Bielefeld, Bielefeld 4800, West Germany

A simple system for displaying alphanumeric characters on an oscilloscope screen is described. It may be useful for those applications in which only a few characters should be shown, but within small time limitations. The system, using an AIM-65 microcomputer, is capable of exposure durations below $100 \mathrm{microsec} /$ character. Possibilities of speeding up the system and designing characters are indicated.

The interface and program described below offer a very simple and inexpensive way to display alpha. numeric characters on an oscilloscope screen. If a Rockwell AIM-65 microcomputer is used, as proposed in this paper, it takes about 90 microsec to write one character ( 5 by 7 dot matrix) on the CRT screen, which is fast enough for many applications in which only a small number of characters must be shown.

The principle of operation (elaborated in Barnig, 1977) is a combination of a line-scanning design, in which the beam scans all possible display points of the screen (as used in video monitors), and a character. scanning mode, in which only the used display points are scanned (as used in vector displays). In our application, the beam (switched off at this time) is directed to the position where the desired character should appear and then, like the beam in a video display, rotated $90 \mathrm{deg}$. It scans all possible display points for any alphanumeric character (the 5 by 7 matrix) and is switched on at appropriate positions (see Figure 1).

\section{DESCRIPTION OF THE SYSTEM}

\section{Hardware}

The greatest advantage of this system is simplicity. If an AIM-65 microcomputer is used, one can profit by using the Monitor-ROM for character generation and the 6522 VIA as a shift register (Mayer-Lindenberg, 1979). Furthermore, the AIM can be employed for experimental control, data acquisition, and evaluation, using BASIC or FORTH.

The interface between the AIM and the oscilloscope (shown in Figure 2) generates the needed ramp-formed voltage to deflect the CRT beam in the $\mathrm{Y}$ direction, whenever the 6522 VIA is loaded (CSA low), and then reads out serially. It may be necessary to connect an amplifier between CB2 and the $Z$ input of the oscilloscope if the input is not TTL compatible.

The whole arrangement (hardware and software) is designed to display one row of, for example, 16 charac-

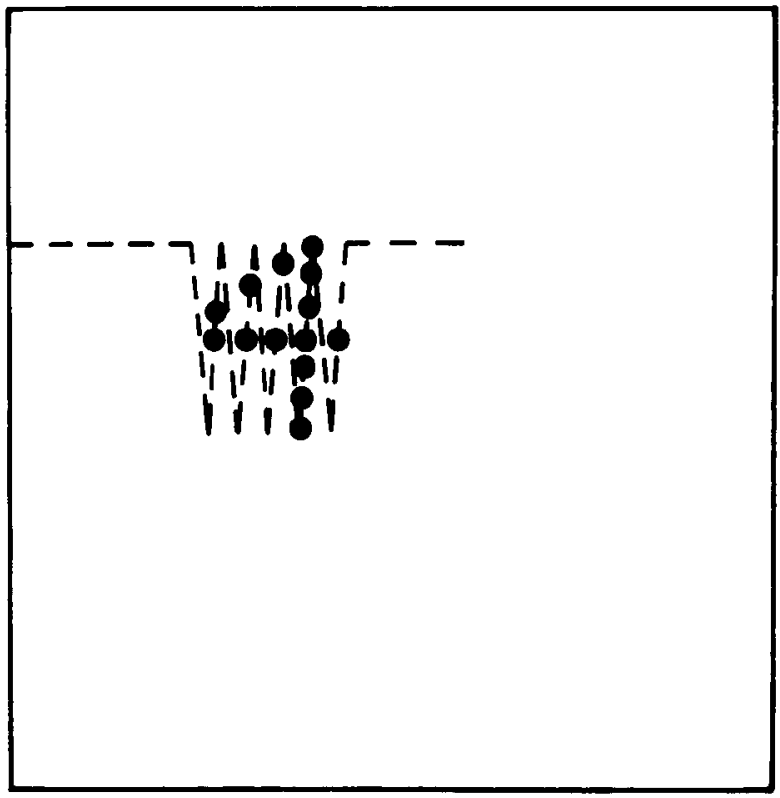

Figure 1. Principle of operation for displaying the number 4.
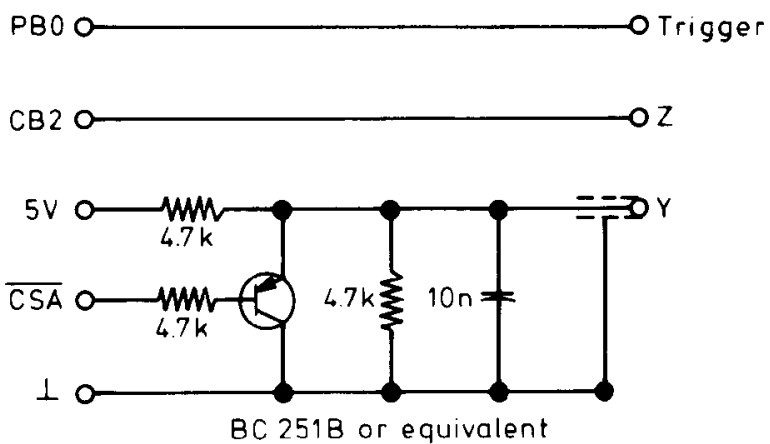

Figure 2. Hardware interface between the AlM-65 and the oscilloscope.

ters, a variable value sufficient for our research. If the user wishes to display characters on several vertical positions, he/she must add the appropriate voltages to the $\mathrm{Y}$ input using, for example, a simple D/A converter supplied by the PB1-PB7 outputs of the 6522 VIA of the AIM.

\section{Software}

The program (listed in Table 1) starts at Position $\$ 0200$ ( $\$$ indicates hexadecimal notation), but it may be shifted to any other area of the memory without modification. Before starting the program, the user must initiate the 6522 VIA,

$$
\begin{aligned}
& \$ A 002: \$ 01(\mathrm{~PB} 0=\text { output }) \\
& \$ A 00 B: \$ 18(\text { shift register control), }
\end{aligned}
$$


Table 1

Disassembled Machine Code for the AIM-65

\begin{tabular}{|c|c|c|}
\hline $\begin{array}{c}\text { Hex } \\
\text { Address }\end{array}$ & Instruction & Comment \\
\hline 0200 & A0 LDY $\# 00$ & Character counter $=$ zero \\
\hline 0202 & A9 LDA \#FE & \\
\hline 0204 & 2D AND A000 & \\
\hline 0207 & 8D STA A000 & $\mathrm{PB} 0=$ low (trigger) \\
\hline $020 \mathrm{~A}$ & B1 LDA (DC),Y & \\
\hline $020 \mathrm{C}$ & 29 AND \#3F & \\
\hline $020 \mathrm{E}$ & AA TAX & \\
\hline $020 \mathrm{~F}$ & BD LDA F $2 E 1, X$ & The first column is loaded \\
\hline 0212 & OA ASL .A & \\
\hline 0213 & 8D STA A00A & \\
\hline 0216 & EA NOP & NOPs important for timing \\
\hline 0217 & EA NOP & \\
\hline 0218 & EA NOP & \\
\hline 0219 & EA NOP & \\
\hline $021 \mathrm{~A}$ & BD LDA F $321, \mathrm{X}$ & The second column \\
\hline $021 \mathrm{D}$ & OA ASL .A & \\
\hline $021 \mathrm{E}$ & 8D STA A00A & \\
\hline 0221 & EA NOP & \\
\hline 0222 & EA NOP & \\
\hline 0223 & EA NOP & \\
\hline 0224 & EA NOP & \\
\hline 0225 & BD LDA F361, $\mathrm{X}$ & \\
\hline 0228 & OA ASL .A & \\
\hline 0229 & 8D STA A00A & \\
\hline $022 \mathrm{C}$ & EA NOP & \\
\hline $022 \mathrm{D}$ & EA NOP & \\
\hline $022 \mathrm{E}$ & EA NOP & \\
\hline $022 \mathrm{~F}$ & EA NOP & \\
\hline 0230 & BD LDA F 3A1, X & \\
\hline 0233 & OA ASL .A & \\
\hline 0234 & 8D STA A00A & \\
\hline 0237 & EA NOP & \\
\hline 0238 & EA NOP & \\
\hline 0239 & EA NOP & \\
\hline $023 \mathrm{~A}$ & EA NOP & \\
\hline $023 B$ & BD LDA F $3 E 1, X$ & \\
\hline $023 \mathrm{E}$ & 0A ASL .A & \\
\hline $023 \mathrm{~F}$ & 8D STA A00A & \\
\hline 0242 & EA NOP & \\
\hline 0243 & EA NOP & \\
\hline 0244 & EA NOP & \\
\hline 0245 & EA NOP & \\
\hline 0246 & A9 LDA \#01 & \\
\hline $0248^{\circ}$ & EA NOP & \\
\hline 0249 & EA NOP & \\
\hline $024 A$ & OD ORA A000 & \\
\hline 024D & 8D STA A000 & $\mathrm{PB} 0=$ high \\
\hline 0250 & C8 INY & \\
\hline 0251 & C0 CPY \#10 & Number of characters \\
\hline 0253 & $30 \mathrm{BMI} 020 \mathrm{~A}$ & All characters written? \\
\hline 0255 & 60 RTS & \\
\hline
\end{tabular}

and set a pointer, which marks the position in RAM where the first character to be displayed is located. The pointer address is \$00DC (LSB) and \$OODD (HSB).

If, for example, \$OODC is loaded with $\$ 89$ and
\$0ODD with \$FF, the access of the processor is directed to Memory Location \$FF89, where the first character of the string "ROCKWELL AIM 65" is stored in the Monitor-ROM; thus, this string is displayed.

The writing of a 16-element character string (three blanks included, one at the beginning) takes less than 2 msec $(16 \times 90$ microsec + the time needed for shifting between the characters). The advantage of this pointer technique is obvious: One can hold several strings in readiness and switch between them by altering only two memory locations. The characters that should be displayed must be stored in their ASCII form (e.g., 65, or $\$ 41$, for $\mathrm{A}$ ). If a BASIC interpreter is available, an easy way to get this form is typing $\operatorname{ASC}$ ('A')

The program is written as a subroutine (it ends with an RTS); so one jumps to it by executing JSR or, coming from BASIC, the appropriate statements described in the AIM-65 BASIC Language Reference Manual (Rockwell International, 1979). If periodical interrupts are used to jump to the display program, the processor registers must be saved beforehand, because they are altered by execution of the program. The number of characters to be displayed is stored in $\$ 0252$, so it can be changed easily.

\section{CONCLUDING REMARKS}

If an external clock and a shift register are used, the system can be speeded up to 40 microsec/character; this is the fastest value attainable by the AIM. One can make use of all characters available to the AIM printer, but beyond this, original characters can be created. For this purpose, a character generator must be written. Each character takes 5 bytes of the RAM if a 5 by 7 dot matrix is chosen. The AIM-65 Monitor Program Listing (Rockwell International, 1978) provides useful hints.

\section{REFERENCES}

BArnia, M. Oszilloskop als alphanumerisches Datensichtgerät. Elektronik, 1977, 26, 92-96.

Mayer-Lindenbero, F. Oszillograph als Bildschirm für den AIM. 65xx Micro Mag, 1979, 8, 33-35.

RockWELl INTERNational. AIM-65 microcomputer monitor program listing (Document No, 29650 N36L). Anaheim, Calif: Author, 1978.

Rockwell Intennational. AIM-65 microcomputer BASIC language reference manual (Document No. 29650 N49). Anaheim, Calif: Author, 1979.

(Accepted for publication November 23, 1982.) 